\title{
1. Introduction to human resource management process
}

\author{
Charmi Patel, Huadong Yang and Karin Sanders
}

\section{INTRODUCTION}

There is a long-standing research tradition in human resource management (HRM) to examine the relationship between human resources (HR) practices and organizational performance. In their attempt to explain the nature of this causal chain, also referred to as the 'black box' problem, many scholars have turned their attention to HR process (see Bowen \& Ostroff, 2004; Hewett et al., 2018; Ostroff \& Bowen, 2016; Sanders, Shipton \& Gomes, 2014; Wang et al., 2020). Much of this was a response to the dominance of HRM content research that was facing challenges in unlocking the black box and demonstrating the dynamics of how HR practices impact organizational and individual outcomes. Led by influential scholars such as Bowen and Ostroff (2004) and Nishii, Lepak and Schneider (2008), the HR process approach pays attention to factors external to HRM practices and emphasizes how HR policies are communicated to employees and how employees make sense of HR practices.

Currently, there have been two main streams in studying HR processes. Bowen and Ostroff's (2004) theoretical framework on HR system strength initiates the first stream of research and focuses on the process of how organizations communicate their HR policies and practices to employees. Bowen and Ostroff (2004) borrow and integrate organizational climate literature (Schneider, Salvaggio \& Subirats, 2002) and Kelley's co-variation model of attribution theory (Kelley, 1967, 1973), proposing that when employees perceive HR in their organization to be distinctive, consistent and consensual, it results in what they described as a 'strong' HR system through which employees can understand what is expected from them and respond accordingly. Their seminal work challenges the default assumptions of the content approach to strategic HRM, highlights the importance of communicating HR strategies, policies and practices to employees and stimulates many empirical studies on HRM system strength. However, by integrating two theories at the different levels - organizational climate at the organizational level and co-variation model of attribution theory at the individual level - their work has brought about a level of confusion to their followers. Although they have repeatedly clarified that HRM system strength should be considered an organizational property (Bowen \& Ostroff, 2004; Ostroff \& Bowen, 2016; see also Chapter 11 in this book), most empirical studies focus on the co-variation model and examine employee-perceived HRM system strength at the individual level (see Chapter 3 of this book). HRM system strength and perceived HRM system strength are just like organizational support and perceived organiza- 
tional support in the field of organizational behaviour. They are both meaningful concepts; however, they capture the different dynamics of HR process.

The second influential strand of HR process research has concentrated on how employees make sense of their organizations' intentions behind the implementation of HR practices, known as HR attributions (Nishii et al., 2008). This perspective draws on the theory of causal attributions (Heider, 1958), which explains how individuals form an understanding of, and respond to, their environment (Kelley \& Michela, 1980; Weiner, 1985). In applying Heider's (1958) internal versus external causal attributions to HR domain, Nishii et al. (2008) first differentiated two general HR attributions: internal attributions describe employees' beliefs that HR practices are designed in response to internal pressures (e.g., department mergers, a change in leadership, or new financial guidelines) and external attributions refer to employees' beliefs that HR practices are designed in response to situational pressures, such as complying with union and legal requirements. They further divided internal attributions into four types as a crossover of the two dimensions of HR philosophy (commitment versus control approach) and HR focus (strategic versus employee focus): service quality, employee well-being, cost reduction and employee exploitation attributions. The emergent conceptual matrix demonstrated that when employees believe that HR practices are intended to enhance employee well-being or increase service quality, they show higher organizational commitment and are more satisfied, which was associated with higher organization citizenship behaviours and customer satisfaction. In contrast, when employees believe that HR practices are designed to intensify work and/or to reduce cost, they are less committed and less satisfied.

In addition to the HR system strength model by Bowen and Ostroff (2004) and the HR attribution model by Nishii and colleagues (2008), the implementation of HR by line managers is also part of HR process research. These three elements of HR process research have stimulated numerous empirical studies. Several review papers (Hewett et al., 2018; Ostroff \& Bowen, 2016; Wang et al., 2020; also see Chapters 2, 3,7 and 12 in this book) have recently appeared in influential journals. The evidence on the impact of HR process has been accumulated and acknowledged. Yet, a lot of questions remain unanswered. For example, what is the nature of HR processes? Is it about communication or about sensemaking, or both or neither? How do HR processes interact with HR content in influencing outcomes? Who are the actors of HR processes: the HR department, line managers, employees, or all of them? Then how do we clarify the role of each party who is involved in HR processes? In this regard, the existing research seems fragmented, developing curiously different citation patterns without much cross-fertilization. For example, most research on HRM system strength to date has centred on the individual level and examined individual perceptions of HRM system strength rather than operationalizing at the organizational level and viewing HRM system strength as a property of organization (Ostroff \& Bowen, 2016). Similarly, equivocal findings regarding the impact of 'control-focused' attribution in different contexts (see, for example, Hewett et al., 2018; Van de Voorde \& Beijer, 2015) raise questions of external validity about the HR attribution typology. Also, on the topic of the implementation of HR by line managers, some important 
questions remain unanswered: what is the role of ability, motivation and opportunities of managers to implement HR in their team or department? What is the spillover effect if the signals from senior managers to line managers are not clear? Needless to say, the three strands of research around HRM system strength and HR attribution run in parallel with work on HR implementation, within an overarching umbrella of attribution theory with different conceptual variations that link HR processes together.

\section{STRUCTURE OF THE BOOK}

Against this backdrop, our book reviews progress and assesses the state of the art of HR process research by highlighting outstanding research questions and discussing future research avenues. We structure our chapters according to three themes. First, we review the state of HR process research, focusing on HR attributions, HR strength and an overview on the methodological issues on HR process research. Second, we extend the discussions and learning to new applications of HR strength and HR attributions in other related areas such as change management, talent management and role of strategic actors (such as top management, HR professionals and line managers) in implementation of HRM policies and practices. Third, we integrate this discussion to management research in general and HR research more specific to develop a greater awareness and appreciation of the strengths and weaknesses of these research streams and provide avenues and questions for further research.

In Part I, Hewett (Chapter 2) has reviewed 17 articles on HR attribution research since Nishii et al.'s (2008) seminal work. Hewett structures her review around three themes: the positioning of HR attributions in the HR process chain, the dimensional structure of HR attributions and the context of HR attributions with respect to specific HR practices. Her review not only highlights the main findings accumulated so far on HR attribution studies but also addresses unanswered questions and provides new avenues for future research. Corresponding to Hewett's review on HR attribution, Sanders, Bednall and Yang (Chapter 3) provide a review on HR strength. Their review emerged from three influential reviews published previously and 41 empirical quantitative papers in the field of HR strength. One of the highlights of their review is on methodological choices. They examined four aspects of validity (internal, external, construct and statistical conclusion validity) against the 41 papers. Their review has implications for how to improve the measures of HR strength and how to design rigorous studies in the field of HR strength. Part I ends with Van Rossenberg's discussion (Chapter 4) on various operationalizations of HRM perceptions and their implications to HR process research. As HRM perceptions are the starting point of HR process research, this chapter is relevant to both perceived HR strength and HR attributions. In this chapter, Van Rossenberg distinguishes the differences of perceptions within groups (between employees or between managers) and perceptions between groups (employees versus managers). Subsequently, she elaborates the the- 
oretical meaning of differences in HRM perceptions in relation to the 'what', 'how' and 'why' questions addressed in HR process research.

In Part II, Zhang, Wang and Wei (Chapter 5) apply the theoretical framework of HR attributions by Nishii et al. (2008) to line managers and offer a nuanced understanding of team leaders' HR attributions and how they further shape line managers' leadership styles and in turn influence employee and team outcomes. In doing so, they offer an integrative framework to study team leaders' HR attributions. Li in Chapter 6 considers HR process as message-based persuasion from management to employees. Based on the elaboration likelihood model, she views HR attribution as a central route related to communicating the quality of HR signals and HR credibility (referring to the extent to which HR professionals are perceived as credible by employees) as the peripheral route. Her work extends our understanding of HR process from a communication perspective. Extending this line of thought, by taking into account the multi-actor process view of HRM implementation, Bos-Nehles, Trullen and Valverde (Chapter 7), address how different strategic actors such as top management, HR professionals and line managers implement HRM policies and practices in ways conducive to stronger HRM systems. Townsend, Cafferkey, Dundon and Riaz (Chapter 8) lament that a more 'conscious' and critical unpacking is needed to examine the process by which HRM is implemented, taking into consideration not only the context but also the collective power dynamics and societal norms and expectations. The authors unpack key debates, assertions, hypotheses and counterclaims in exploring how HRM might influence performance outcomes as one of its most difficult problems to untangle. Furthering the understanding of context, chapters by Bish, Shipton and Jorgenson (Chapter 9) as well as Sanders and Rafferty (Chapter 10) underscore the application of HR attributions to talent and change management, respectively. In particular, Bish et al. apply the principles of attribution theory to understand how individuals perceive talent management, and how attributions about talent management may influence employee outcomes. Inspired by perceived HR strength and HR attributions, Sanders and Rafferty introduce the constructs of 'change attribution' and 'change strength' as process-related factors that explain how employees perceive and making sense of organizational change. Their work shows the influence of HR process research in other management fields.

In Part III, our concluding chapters by field veterans Ostroff (Chapter 11) and Guest (Chapter 12) aptly reflect the current state of HR process research as well as offer suggestions for future research. Ostroff, fittingly, talks about the need to consider different theoretical underpinnings of what (HR practices and systems), how (HR process and system strength), why (HR attributions) and who (HR agents) domains of the HR landscape. In doing so, she reflects on the need for researchers to be careful in constructing the meaning of each construct, its operationalization and measurement across different levels of analyses. Guest takes on the fundamental question and the long-overlooked role of front-line managers in implementing HRM practices and policies. By taking a stakeholder approach, he first presents the challenges front-line managers face in implementing effective HRM processes. Replying on the ability-motivation-opportunity framework, he then analyses the qualities 
required for front-line managers to deal effectively with HR implementation issues. He ends the chapter by addressing the importance of management environment in front-line HR implementation. He points out that all these required qualities function well only in a flexible situation that provides autonomy to and encourages proactivity of front-line managers.

In sum, the Handbook on HR Process Research presents chapters that demonstrate state-of-the-art research by prominent scholars around the globe on HR process research. The theorizing, research findings and future research directions concerning HR process research in this book open up new avenues for research, not only in the HRM field but also across disciplines to investigate the black box of the HRM-performance relationship. In addition to the topics outlined in the chapters, scholars may wish to consider the heterogeneity of contexts in other areas of HR process not outlined in this book. In conclusion, we hope that this book serves as a touchstone for future research and will attract a broader global audience of scholars and practitioners.

\section{REFERENCES}

Bowen, D.E., \& Ostroff, C. (2004). Understanding HRM-firm performance linkages: The role of 'strength' of the HRM system. Academy of Management Review, 29, 203-21.

Heider, F. (1958). The Psychology of Interpersonal Relations. Eastford, CT: Martino Publishing.

Hewett, R., Shantz, A., Mundy, J., \& Alfes, K. (2018). Attribution theories in human management research: A review and research agenda. International Journal of Human Resource Management, 29(1), 87-126.

Kelley, H.H. (1967). Attribution theory in social psychology. In D. Levine (ed.), Nebraska Symposium on Motivation (pp. 192-238). Lincoln, NE: University of Nebraska Press.

Kelley, H.H. (1973). The processes of causal attribution. American Psychologist, 28(2), 107-28.

Kelley, H.H., \& Michela, J.L. (1980). Attribution theory and research. Annual Review of Psychology, 31(1), 457-501.

Nishii, L.H., Lepak, D.P., \& Schneider, B. (2008). Employee attributions of the 'why' of HR practices: Their effects on employee attitudes and behaviors, and customer satisfaction. Personnel Psychology, 61, 503-45.

Ostroff, C., \& Bowen, D.E. (2016). Reflections on the 2014 Decade Award: Is there strength in the construct of HR system strength? Academy of Management Review, 41(2), 196-214.

Sanders, K., Shipton, H., \& Gomes, J. (2014). Is HR process important? Past, current \& future challenges. Human Resource Management, 53, 489-503.

Schneider, B., Salvaggio, A.N., \& Subirats, M. 2002. Climate strength: A new direction for climate research. Journal of Applied Psychology, 87, 220-29.

Van de Voorde, F.C., \& Beijer, S. (2015). The role of employee HR attributions in the relationship between high-performance work systems and employee outcomes. Human Resource Management Journal, 25, 62-78.

Wang, Y., Kim, S., Rafferty, A., \& Sanders, K. (2020). Employee perceptions of HR practices: A critical review and future directions. The International Journal of Human Resource Management, 31(1), 128-73.

Weiner, B. (1985). 'Spontaneous' causal thinking. Psychological Bulletin, 97(1), 74-84. 